\title{
Chapter 3 \\ Innovation in Earth Observations \\ as a National Strategic Investment: The Experience of the U.S.
}

\author{
Masami Onoda and Molly Macauley
}

\subsection{U.S. Earth Observation Strategy}

Earth observations can provide actionable science and information for policy through projections and forecasts; near real-time management or identification of deviations in long-term trends; and improved spatial, spectral, or temporal resolution (and better characterization of uncertainty) in data, observations, and models. Earth observations are regularly used by the media and interested members of the public, with the capacity to visualize large amounts of quantitative data using today's technology infrastructure.

\footnotetext{
Molly Macauley—Deceased

Dr. Molly Macauley was invited as a member of the PEOIC International Advisory Board and joined the workshop in Tokyo in November 2015. In a tragic incident Dr. Macauley passed away on July 8, 2016, her contribution for this book yet to be completed. The following article was written by Dr. Masami Onoda on Dr. Macauley's behalf, with permission from her institute, based on Dr. Macauley's presentation at the Tokyo workshop. Molly's dedication and expertise with which she made such an enormous contribution to the study of the benefits of space will never be forgotten, including this valuable piece of work with our group. It has truly been an honor and privilege to work with her.
}

\author{
M. Onoda (ه) \\ International Relations and Research Department, Japan Aerospace Exploration Agency, \\ Ochanomizu Sola City, 4-6, Kanda Surugadai, Chiyoda-Ku, Tokyo 101-8008, Japan \\ e-mail: onoda.masami@jaxa.jp \\ M. Macauley \\ Resources for the Future (RFF), 1616 P St. NW, Suite 600, Washington, DC 20036, USA
}

(C) The Author(s) 2017

M. Onoda and O.R. Young (eds.), Satellite Earth Observations and Their

Impact on Society and Policy, DOI 10.1007/978-981-10-3713-9_3 


\subsubsection{National Space Policy of the U.S.}

The U.S. policy for Earth observation is set out in the National Space Policy of the United States of America (Executive Office of the President 2010), and includes an emphasis on expanding and identifying international cooperation opportunities. The Policy states in its introduction that: "the United States hereby renews its pledge of cooperation in the belief that with strengthened international collaboration and reinvigorated U.S. leadership, all nations and peoples-space-faring and space-benefiting - will find their horizons broadened, their knowledge enhanced, and their lives greatly improved." The goals of the Policy include: "expand international cooperation on mutually beneficial space activities to: broaden and extend the benefits of space; further the peaceful use of space; and enhance collection and partnership in sharing of space-derived information." In the section on international cooperation, the Policy advocates open access to Earth observation data by promoting "the adoption of policies internationally that facilitate full, open, and timely access to government environmental data." The Policy further states that "departments and agencies shall identify potential areas for international cooperation that may include, but are not limited to: space science; space exploration, including human space flight activities; space nuclear power to support space science and exploration; space transportation; space surveillance for debris monitoring and awareness; missile warning; Earth science and observation; environmental monitoring; satellite communications; global navigation satellite systems (GNSS); geospatial information products and services; disaster mitigation and relief; search and rescue; use of space for maritime domain awareness; and long-term preservation of the space environment for human activity and use." In the section Environmental Earth Observation and Weather, the Policy stresses the use of international partnerships to help sustain and enhance weather, climate, ocean, and coastal observation from space.

\subsubsection{National Plan for Civil Earth Observations}

The U.S. National Plan for Civil Earth Observations (National Science and Technology Council, Executive Office of the President 2014) defines a new framework for constructing a balanced portfolio of Earth observations and observing systems. This framework classifies Earth observation activities according to two broad categories - sustained and experimental - based on the duration of the anticipated Federal commitment:

- Sustained observations are defined as measurements taken routinely that Federal agencies are committed to monitoring on an ongoing basis, generally for 7 years or more. These measurements can be for public services or for Earth system research in the public interest. 
- Experimental observations are defined as measurements taken for a limited observing period, generally 7 years or less, that Federal agencies are committed to monitoring for research and development purposes. These measurements serve to advance human knowledge, explore technical innovation, and improve services, and in many cases may be first-of-their-kind Earth observations.

Based on this framework and the results of the Earth Observation Assessment $(\mathrm{EOA}){ }_{1}^{1}$ the National Plan establishes the following rank-ordered priorities:

1. Continuity of sustained observations for public services

2. Continuity of sustained observations for Earth system research

3. Continued investment in experimental observations

4. Planned improvements to sustained observation networks and surveys for all observation categories

5. Continuity of, and improvements to, a rigorous assessment and prioritization process.

Action $7^{2}$ of the Plan states: "Maintain and Strengthen International Collaboration. The global nature of many Earth observations and the value of these observations to U.S. Government decision-makers require U.S. agencies to carry out their missions through collaboration with foreign agencies, international organizations, and standards/coordination groups. Through international collaboration, U.S. agencies leverage foreign data and scientific expertise to improve their understanding of remote areas, such as the open ocean and polar regions, and to characterize global atmospheric, oceanic, and terrestrial phenomena. In addition, collaboration with international partners helps to minimize unnecessary redundancy in the collection of Earth observations, and ensures the effective use of limited resources. U.S. agencies also work closely with the Department of State and other agencies to provide associated scientific and technical support for U.S. foreign policy, security, economic, and environmental interests."

\subsubsection{A Plan for a U.S. National Land Imaging Program}

For land observations, a plan for a U.S. national land imaging program (Future of Land Imaging Interagency Working Group, Executive Office of the President 2007) was initiated as an "effort to develop a long-term plan to achieve technical, financial, and managerial capability for operational land imaging in accord with the goals and objectives of the U.S. Integrated Earth Observation System." Noting that the "importance of this imagery to the Nation requires a more sustainable effort to ensure that land imaging data are available far into the future," it was developed as

\footnotetext{
${ }^{1}$ See Chap. 2 of the U.S. National Strategy for Civil Earth Observations (National Science and Technology Council, Executive Office of the President 2013).

${ }^{2}$ See Sect 4.2 .7 of the National Plan for Civil Earth Observations (National Science and Technology Council, Executive Office of the President 2014)
} 
"a plan that identifies options for future civil land imaging data acquisition, establishes an implementation strategy, and recommends a governance and management structure to ensure that future U.S. land imaging needs will be met." "It presents a set of policy recommendations to achieve a stable and sustainable U.S. operational space-based land imaging capability and to ensure continued U.S. scientific, technological, and policy leadership in civil land imaging and the scientific disciplines it supports."

\subsubsection{Decadal Survey for Earth Science and Applications from Space}

The so-called "Decadal Survey" (National Academy of Sciences 2007) is based on the request of NASA, the National Oceanic and Atmospheric Administration (NOAA)/National Environmental Satellite, Data, and Information Service (NESDIS), and the U.S. Geological Survey (USGS) to conduct a decadal survey to generate consensus recommendations for the Earth and environmental science and applications communities regarding a systems approach to space-based and ancillary observations that encompasses the research programs of NASA; the related operational programs of NOAA; and associated programs such as Landsat - a joint initiative of USGS and NASA.

The last Decadal Survey for Earth Science and Applications from Space was published in 2007 (National Academy of Sciences 2007). The Decadal Survey for 2017-2027 is now ongoing. In the current survey, its "prioritization of research activities will be based on the committee's consideration of identified science priorities; broad national operational observation priorities as identified in U.S. government policy, law, and international agreements (for example, the 2014 National Plan for Civil Earth Observations) and the relevant appropriation and authorization acts governing NASA, NOAA, and USGS; cost and technical readiness; the likely emergence of new technologies; the role of supporting activities such as in situ measurements; computational infrastructure for modeling, data assimilation, and data management; and opportunities to leverage related activities including consideration of interagency cooperation and international collaboration...The survey committee will work with NASA, NOAA, and USGS to understand agency expectations of future budget allocations and design its recommendations based on budget scenarios relative to those expectations. The committee may also consider scenarios that account for higher or lower than anticipated allocations... The committee may also identify potential interagency and international synergies; proposed augmentations to planned international missions; and adjustments to U.S. missions planned, but not yet implemented."

The use of Earth observations for policy include a variety of areas such as: agricultural crop production, atmosphere-ocean coupled general circulation models (with $\mathrm{CO}_{2}$ damages being quantified and the dollar value of damage being applied to the cost of new appliances for purposes of establishing minimum energy 
efficiency standards in the U.S.), direct input to the work of the Intergovernmental Panel on Climate Change (IPCC), the application of Gravity Recovery and Climate Experiment-Data Assimilation System (GRACE-DAS) to the U.S. Drought Monitor Weekly Mapping Process, weather projections and forecasts; near real-time adaptive management or identification of deviation in long-term trends; and cyber infrastructure.

The aforementioned assessments and surveys rely upon various methods to judge impact and rank priorities. Earth observation projects almost always provide information as their primary output. If decision-makers who are the primary users of the project's output are available to assist, then Value of Information (VOI) methods can be used (NASA Earth Science Applied Sciences Program 2012).

\subsection{Quantifying the Economic Value of Information}

VOI methods, which are primarily prospective, measure how new information changes a decision-maker's prior beliefs about uncertainties and the value the decision-maker would derive from the resulting change (NASA Earth Science Applied Sciences Program 2012).

VOI is a concept that enables the integration of the economic value of satellite data into economic analyses. The idea that information has value in both a statistical and a pragmatic sense dates back at least to the 1950s. In recent years, interest in the economic VOI has taken center stage. In the field of space studies, this refers to innovations in the technologies that collect information; this is the new information provided by the growing number of Earth-orbiting satellites, an area where recent applications of VOI methods are critically important for informing investment in satellite networks (Laxminarayan and Macauley 2012).

The following are VOI principles that are relevant for Earth observation:

- Information has value if it can either make a current choice more secure and confident or if it can reveal a different choice as better than the current choice;

- Information may lead to recognition that there is more uncertainty than initially thought;

- Information has value even if it introduces more uncertainty (it reveals that what was thought to be certain may not be);

- Perfect information may not be worth the cost of acquisition;

- Some attributes of information may confer more value than others (e.g., spatial, temporal, and spectral resolution; accuracy, precision, and other statistical properties of the distribution of information);

- Information tends to have value if it enables an action or a decision;

- Information, once acquired, is available at low additional cost, and one person's use may not preclude another person's use. Some information is about goods and services for which no prices exist. 
Fig. 3.1 Value of forecast and standard error [reproduced from Agnew and Anderson (1977)]

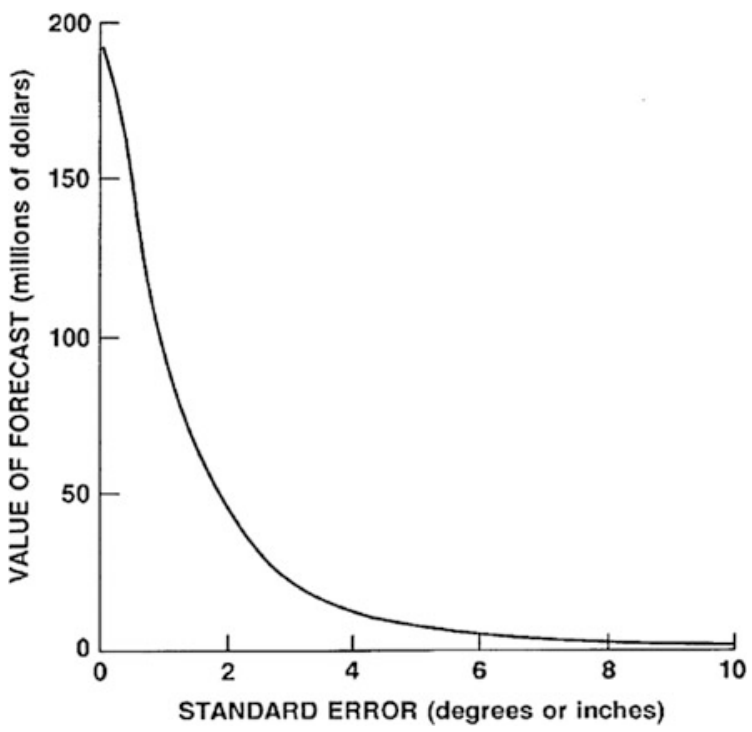

\subsubsection{Forecast Error Contribution and VOI}

As early as 1977, Agnew and Anderson described the exponential relationship between standard error and the value of forecast (see Fig. 3.1).

Forecast Error Contribution (FEC) can be used to measure the impact of individual observing systems, and therefore the value of their information. Figure 3.2 shows, for $24 \mathrm{~h}$ forecasts, the distribution of FEC (in percent) for the different observation types summed (top panel) and single observation normalized (bottom panel). It shows that the Advanced Microwave Sounding Unit-A (AMSU-A) is the single most valuable source of data, while buoy data are one of the most important components of the conventional observing system. According to the bottom panel, buoy impact per single observation is by far the largest among all different kinds of observations (Radnóti et al. 2012).

\subsubsection{Examples and Further Reading}

There are various methods and examples of Earth observation VOI analyses. Bernknopf et al. (2012) describe an economic model that involves application of geospatial data to land use and air quality regulation. Bouma et al. (2009) conducted a study on monitoring water quality. Econometric modeling and estimation examples include studies on agricultural productivity (Tenkorang and Lowenberg-DeBoer 2008); life expectancy (Obersteiner et al. 2012); and other quality of life dimensions. Simulation modeling and estimation is another method, 

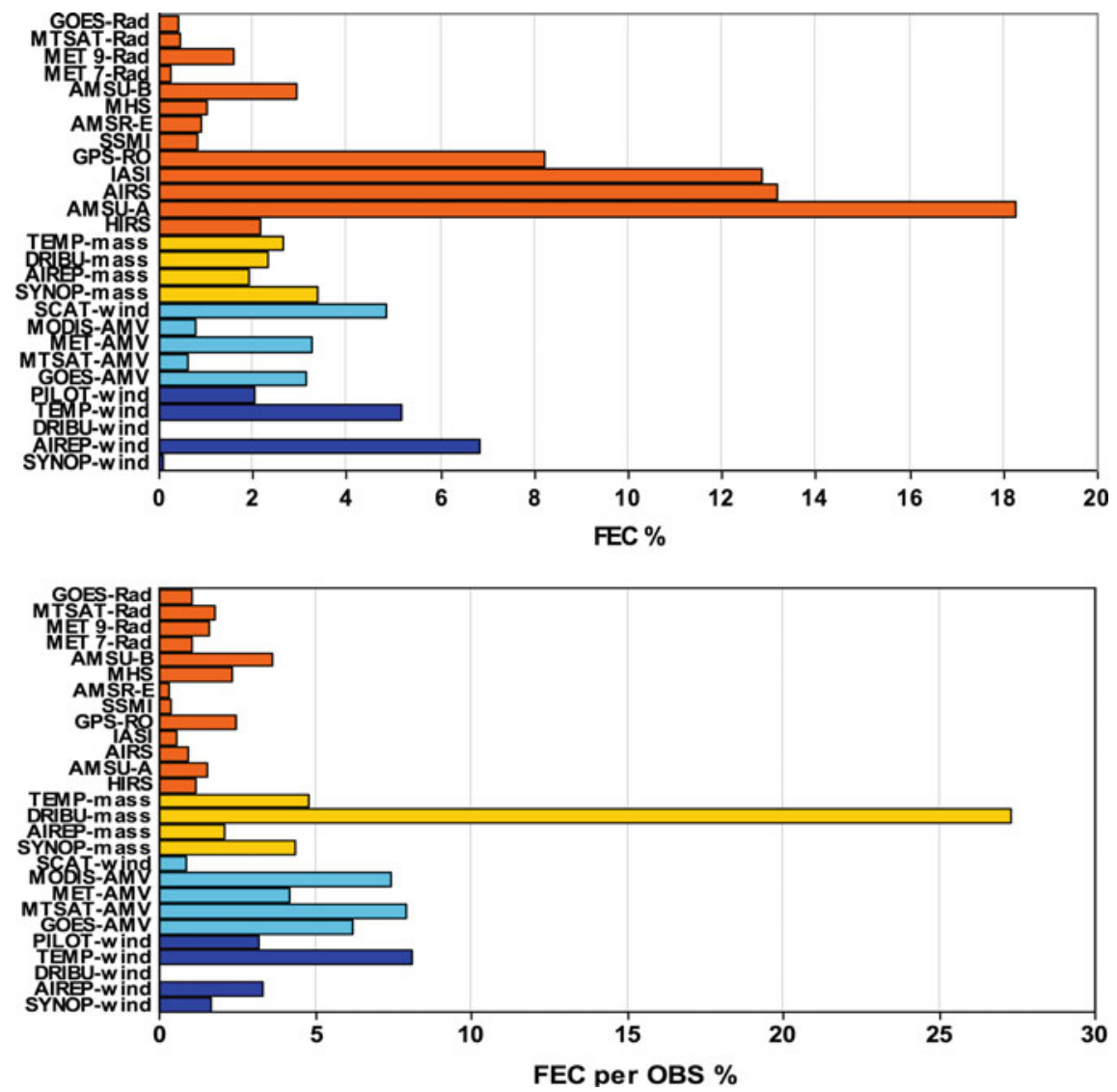

Fig. 3.2 FEC distribution for different observation types summed (top panel) and normalized for a single observation (bottom panel). The FEC is displayed in $\%$ and it is derived for $24 \mathrm{~h}$ forecast errors. Reproduced from Radnóti et al. (2012)

while price- and cost-based derivation studies include weather data for weather insurance (Osgood and Shirley 2012); drought and land use information for index insurance (Skees 2008); and losses averted from vector-borne disease (Hartley 2012). Probabilistic approaches include Bayesian belief networks (Kousky and Cooke 2012) and expert elicitation (Interagency Working Group on Social Cost of Carbon 2010). These studies are described in detail in "The Value of Information" (Laxminarayan and Macauley 2012). 


\section{References}

Agnew CE, Anderson RJ (1977) The economic benefits of improved climate forecasting. Princeton, New Jersey

Bernknopf RL et al (2012) Estimating the benefits of land imagery in environmental applications: a case study in nonpoint source pollution of groundwater. In: Laxminarayan R, Macauley MK (eds) The value of information: methodological frontiers and new applications in environment and health. Springer, Netherlands, pp 257-299

Bouma JA et al (2009) Assessing the value of information for water quality management in the North Sea. J Env Man 90(2):1280-1288

Executive Office of the President (2010) National space policy of the United States of America. https://www.whitehouse.gov/sites/default/files/national_space_policy_6-28-10.pdf. Accessed 29 Nov 2016

Future of Land Imaging Interagency Working Group, Executive Office of the President (2007) A plan for a U.S. national land imaging program. https://eros.usgs.gov/sites/all/files/external/ eros/history/2000s/2007\%20A\%20Plan\%20for\%20U.S.\%20National\%20Land\%20Imaging \%20Program.pdf. Accessed 29 Nov 2016

Hartley DM (2012) Space imaging and prevention of infectious disease: rift valley fever. In: Laxminarayan R, Macauley MK (eds) The value of information: methodological frontiers and new applications in environment and health. Springer, Netherlands, pp 231-243

Interagency Working Group on Social Cost of Carbon (2010) Social cost of carbon for regulatory impact analysis. https://www.whitehouse.gov/sites/default/files/omb/inforeg/for-agencies/ Social-Cost-of-Carbon-for-RIA.pdf. Accessed 29 Nov 2016

Kousky C, Cooke RM (2012) The value of information in a risk management approach to climate change. In: Laxminarayan R, Macauley MK (eds) The value of information: methodological frontiers and new applications in environment and health. Springer, Netherlands, pp 19-43

Laxminarayan R, Macauley MK (2012) The value of information: methodological frontiers and new applications in environment and health. Springer, Netherlands

NASA (2012) Applied sciences program 2011 annual report. Washington, D.C., USA

National Academy of Sciences (2007) Earth science and applications from space: national imperatives for the next decade and beyond. https://www.nap.edu/catalog/11820/earth-scienceand-applications-from-space-national-imperatives-for-the. Accessed 29 Nov 2016

National Science and Technology Council, Executive Office of the President (2013) National strategy for civil Earth observations. https://www.whitehouse.gov/sites/default/files/microsites/ ostp/nstc_2013_earthobsstrategy.pdf. Accessed 29 Nov 2016

National Science and Technology Council, Executive Office of the President (2014) National plan for civil earth observations. https://www.whitehouse.gov/sites/default/files/microsites/ostp/ NSTC/national_plan_for_civil_earth_observations_-_july_2014.pdf. Accessed 29 Nov 2016

Obersteiner $M$ et al (2012) Valuing the potential impacts of GEOSS: a systems dynamics approach. In: Laxminarayan R, Macauley MK (eds) The value of information: methodological frontiers and new applications in environment and health. Springer, Netherlands, pp 67-90

Osgood D, Shirley KE (2012) The value of information in index insurance for farmers in Africa. In: Laxminarayan R, Macauley MK (eds) The value of information: methodological frontiers and new applications in environment and health. Springer, Netherlands, pp 1-18

Radnóti $G$ et al (2012) ECMWF study to quantify the interaction between terrestrial and space-based observing systems on numerical weather prediction skill. http://www.ecmwf.int/ sites/default/files/elibrary/2012/11814-ecmwf-study-quantify-interaction-between-terrestrialand-space-based-observing-systems.pdf. Accessed 29 Nov 2016 
Skees JR (2008) Innovations in index insurance for the poor in lower income countries. Agric Resour Econ Rev 37(1):1-15

Tenkorang F, Lowenberg-DeBoer J (2008) On-farm profitability of remote sensing in agriculture. J Terre Obs 1(1):50-59

\section{Author Biographies}

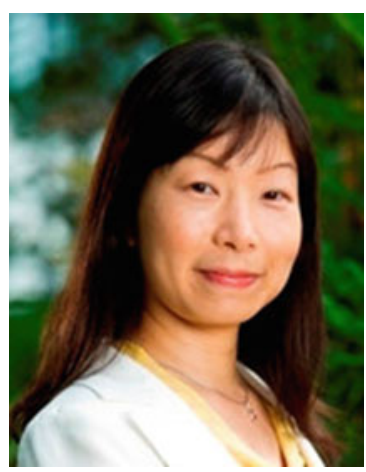

Masami Onoda is currently the U.S. and multilateral relations interface at the International Relations and Research Department of the Japan Aerospace Exploration Agency (JAXA). As an academic, she is fellow of the Institute of Global Environmental Strategies (IGES) and she is also engaged in the private sector as an advisor to the Singapore-based space debris start-up Astroscale Pte. Ltd. since its foundation in 2013. From 2009 to 2012, Dr. Onoda was a scientific and technical officer at the intergovernmental Group on Earth Observations (GEO) Secretariat in Geneva, Switzerland. From 2003 to 2008, while pursuing her graduate studies, she was invited to the JAXA Kansai Satellite Office in Higashiosaka as a space technology coordinator to support technology transfer to SMEs for the small satellite project SOHLA-1. From 1999 to 2003, she worked in the field of Earth observations at JAXA (then NASDA), serving on the Secretariat of the Committee on Earth Observation Satellites (CEOS). In 1999, she was seconded to the UN Office for Outer Space Affairs (UNOOSA) for the organization of the UNISPACE III conference. She holds a Ph.D. in global environmental studies (2009) and a master's degree in environmental management (2005), both from the Kyoto University Graduate School of Global Environmental Studies. Her undergraduate degree is in international relations from The University of Tokyo.

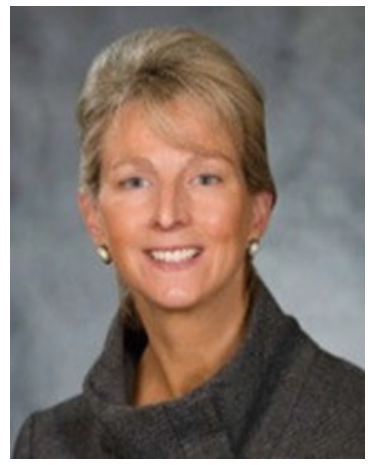

Molly Macauley was vice president for research and senior fellow with Resources for the Future (RFF), Washington, DC. RFF was established at the request of President Truman as a think tank focusing on the economics of natural resources. Her research emphasized new technology and its application to natural and environmental resources, including the value of satellite-derived Earth science information and its use in understanding ecological systems and human relationships with these systems, and the value placed by the public on the nation's space activities. Dr. Macauley frequently testified before Congress and served on national-level committees and panels, including the Committee on Earth Science and Applications from Space of the National Research Council's Space Studies Board, the Board of Advisors for the Thomas Jefferson Public Policy Program at the College of William and Mary, the Science Advisory Board of the National Oceanic and Space Administration, the Earth Science Applications Advisory Group of NASA, and the Scholarship Committee of the Women in Aerospace Foundation. She also served as a lead author for NASA on a synthesis and assessment 
report for the U.S. Climate Change Science Program on the use of Earth observations. She was selected as a "Rising Star" by the National Space Society, was elected to membership of the International Academy of Astronautics, served as a distinguished visitor at the invitation of the Government of Quebec, and received awards for her work from NASA and the Federal Aviation Administration. Molly published extensively with more than 80 journal articles, books, and chapters of books. She was also a visiting professor in the Department of Economics at Johns Hopkins University. Her Ph.D. and M.A. degrees in economics were from Johns Hopkins University and her undergraduate degree in economics was from the College of William and Mary.

In a tragic incident Dr. Macauley passed away on July 8, 2016. This book is dedicated to Dr. Macauley, an inspirational contributor to the project, whose expertise in space policy and economics will always provide invaluable guidance to the space community.

Open Access This chapter is licensed under the terms of the Creative Commons Attribution 4.0 International License (http://creativecommons.org/licenses/by/4.0/), which permits use, sharing, adaptation, distribution and reproduction in any medium or format, as long as you give appropriate credit to the original author(s) and the source, provide a link to the Creative Commons license and indicate if changes were made.

The images or other third party material in this chapter are included in the chapter's Creative Commons license, unless indicated otherwise in a credit line to the material. If material is not included in the chapter's Creative Commons license and your intended use is not permitted by statutory regulation or exceeds the permitted use, you will need to obtain permission directly from the copyright holder.

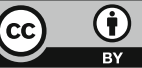

